\title{
Impact of screening for risk of suicide: randomised controlled trial
}

Mike J. Crawford, Lavanya Thana, Caroline Methuen, Pradip Ghosh, Sian V. Stanley,

Juliette Ross, Fabiana Gordon, Grant Blair and Priya Bajaj

\section{Background}

Concerns have been expressed about the impact that screening for risk of suicide may have on a person's mental health.

\begin{abstract}
Aims
To examine whether screening for suicidal ideation among people who attend primary care services and have signs of depression increases the short-term incidence of feeling that life is not worth living.
\end{abstract}

\section{Method}

In a multicentre, single-blind, randomised controlled trial, 443 patients in four general practices were randomised to screening for suicidal ideation or control questions on health and lifestyle (trial registration: ISRCTN84692657). The primary outcome was thinking that life is not worth living measured 10-14 days after randomisation. Secondary outcome measures comprised other aspects of suicidal ideation and behaviour.

\section{Results}

A total of 443 participants were randomised to early $(n=230)$ or delayed screening $(n=213)$. Their mean age was 48.5 years (s.d. $=18.4$, range $16-92)$ and $137(30.9 \%)$ were male. The adjusted odds of experiencing thoughts that life was not worth living at follow-up among those randomised to early compared with delayed screening was $0.88(95 \% \mathrm{Cl} 0.66-$ 1.18). Differences in secondary outcomes between the two groups were not seen. Among those randomised to early screening, 37 people (22.3\%) reported thinking about taking their life at baseline and $24(14.6 \%)$ that they had this thought 2 weeks later.

\section{Conclusions}

Screening for suicidal ideation in primary care among people who have signs of depression does not appear to induce feelings that life is not worth living.

\section{Declaration of interest}

None.
Suicide is a major cause of premature mortality, which results in over 1 million deaths worldwide per year. ${ }^{1}$ Previous research demonstrating high levels of contact with primary care in the period prior to completed suicide ${ }^{2-4}$ has highlighted the role that such services might play in efforts to reduce the incidence of suicide. ${ }^{5}$ A central component of guidelines for the assessment and treatment of depression in primary care is asking patients about suicidal ideas and intent. ${ }^{6}$ Despite the emphasis placed on screening for risk of suicide among people with signs of depression, studies have found low levels of assessment among people treated in primary care. ${ }^{7-9}$ Reasons for this include concerns about the impact on patients of being asked such questions., ${ }^{8,10}$ In a vignettes-based study of 170 general practitioners (GPs) in Germany, 1 in 5 stated that they would not assess suicide risk among elderly patients with depression because they feared that asking such questions could 'induce' suicidal thoughts and behaviour. ${ }^{11}$ A more recent survey of GPs in England revealed that a quarter believed that screening for suicidal ideation could induce a person to have thoughts of selfharm. ${ }^{12}$ General practitioners that took part in this study stated that young people and those with personality disorder may be especially susceptible to the effects of being asked such questions.

Support for the notion that suicidal ideation can be 'transmitted' by exposure to this subject comes from observational studies showing clustering of suicidal behaviour on in-patient mental health units ${ }^{13}$ and short-term increase in the incidence of suicidal behaviour following media coverage of incidents of suicide. ${ }^{14-16}$

It has been argued that before screening for health-related problems is introduced, the potential harms as well as potential benefits need to be examined. ${ }^{17}$ The impact of screening for suicidal ideation among people with signs of depression in primary care has not been examined. An official inquiry into methods for preventing suicide in the USA concluded that, for this reason, screening for suicide risk in primary care could not be supported. ${ }^{18}$ In the light of the uncertainty about the impact of screening for suicidal ideation in primary care, we set out to conduct a clinical trial among people who have signs of depression and are treated in this setting. Our primary aim was to find out whether being screened for suicidal ideation had a short-term impact on the extent to which patients subsequently felt that their life was not worth living.

\section{Method}

We conducted a randomised trial (trial registration: ISRCTN84692657) among people attending primary care services in north and west London. We recruited study participants from four practices where we had established links with local clinicians. The practices are all in inner-city areas that have a relatively young and ethnically diverse population. ${ }^{19}$ The practices each serve between 7000 and 9000 local residents. Recruitment took place over a 22-month period (March 2007 to December 2008).

\section{Study procedures}

People registered with these practices who were aged over 18 were screened for depression using a two-item screening questionnaire ('During the past month, have you often been bothered by feeling down, depressed or hopeless?' and 'During the past month, have you often been bothered by little interest or pleasure in doing things?'). ${ }^{20}$

Those who responded 'yes' to either or both items were given written and verbal information about the study and asked to provide consent to take part. In most instances a researcher (P.B. or L.T.) asked the screening questions prior to the clinical 
consultation. In a minority of instances, clinical staff working in the practice used the screening questions during the clinical consultation or as part of routine health checks.

Potential participants were told that we were conducting a clinical trial that aimed to find out how people respond to being screened for 'health and emotional problems' - no mention was made of depression, suicidal thoughts or behaviour. Those who agreed to take part in the study and had sufficient command of English to complete the baseline interview were randomised to screening for suicidal ideation or questions on health and lifestyle. We used simple randomisation based on a central computergenerated list. All study participants were interviewed on the telephone on two occasions separated by between 10 and 14 days. During the first of these interviews, which was usually conducted by the researcher that recruited the participant (P.B. or L.T.), we repeated the two-item screening questionnaire for depression, collected basic demographic data and assessed participants' mental health using the 12-item General Health Questionnaire (GHQ). ${ }^{21}$ A score of three or more on this questionnaire is taken to indicate caseness. $^{22}$ In addition, participants were asked six further questions on either suicidal ideation and behaviour or health and lifestyle depending on their allocation status.

Questions on suicidal ideation and behaviour were based on those widely used in previous studies examining public mental health ${ }^{23-25}$ which have been recommended as helpful for assessing suicide risk. ${ }^{26}$ They were: 'In the last 2 weeks: Have you felt that life was not worth living? Have you wished that you were dead - for instance, that you would go to sleep and not wake up? Have you thought of taking your life even if you would not really do it? Have you seriously considered taking your life? Have you attempted to take your life?' We also asked participants about exposure to suicidal behaviour among people close to them as this has been highlighted as an important factor to consider when assessing for risk of suicide. ${ }^{26}$ We asked participants: 'Has any member of your family or someone else you are close to attempted to harm themselves or commit suicide in the past?' Control questions on diet and lifestyle were taken from the Preventive Nutrition Project. ${ }^{27}$

All follow-up interviews were conducted by a different researcher who was masked to the participant's allocation status. On this occasion all participants were asked the six questions on suicidal ideation and behaviour. In response to concerns expressed by some healthcare professionals that people with personality disorder may be susceptible to negative effects of screening for suicidal ideation, ${ }^{12}$ we used an eight-item screening tool to assess personality (the Standardised Assessment of Personality Abbreviated Scale, SAPAS) ${ }^{28}$ We used a cut-off point of three or more on the SAPAS to indicate 'probable personality disorder'. Finally, we asked four questions on social support taken from the Close Persons' Questionnaire. ${ }^{29}$

When participants described thoughts that life was not worth living the researcher made further assessment of suicide risk, encouraged the person to make use of resources already available to them (such as discussing their feelings with healthcare staff), and provided information about helplines and other sources of help. In rare instances where participants reported suicidal plans, the researcher asked for verbal consent to contact clinical staff on their behalf. Brent Medical Ethics Committee approved the study prior to the start of data collection (06/Q048/73).

\section{Sample size}

Data from a previous population-based study of mental health in England suggests that $31 \%$ of people who have evidence of depression have thought that life was not worth living during the previous week. ${ }^{25}$ In order to have $80 \%$ power and $5 \%$ level of significance to detect an increase in the proportion who felt their life was not worth living from 30 to $45 \%$, we needed to recruit a sample of 326 individuals. To take account of the clustered nature of the study sample and in anticipation of $15 \%$ loss to follow-up we increased the sample size to 429 participants.

\section{Data analysis}

All analyses were based on the intention-to-treat principle using a complete case analysis. Simple descriptive statistics were used to examine differences in the characteristics of those randomised to screening for suicidal ideation or questions on health and lifestyle. Differences in primary and secondary outcomes were examined by calculating odds ratios (OR) with $95 \%$ confidence intervals (95\% $\mathrm{CI}$ ). To identify factors associated with feeling life was not worth living during the follow-up interview, we used hierarchical logistic regression. All potential confounders (both demographic variables such as age and gender and clinical factors such as mental health) and interaction terms were included in the first step. The non-significant terms were eliminated one by one until the final model was obtained. The statistical methodology used in the analysis took account of the hierarchical structure of the data: people nested within general practices. This was an important consideration since we expected people from the same service to have more in common than people from other services. This analysis was carried out by gllamm, a programme written in STATA for Windows, version 10.

\section{Results}

The trial profile is shown in Fig. 1. In total, 443 people were recruited. Their mean age was 48.5 years (s.d. $=18.4$, range $16-$ 92), 137 (30.9\%) were male and $191(43.1 \%)$ participants were married or in long-term relationships. Of the 421 that provided information about employment status, 201 (47.7\%) were working or in training, 134 (31.87\%) were unemployed and 86 (20.4\%) were retired. All participants scored at least one out of two on the two depression screening questions, with 255 (57.6\%) scoring positively on both. Mean score on the GHQ was 5.5 (s.d.=3.6), with $278(62.8 \%)$ meeting threshold for psychiatric caseness. Overall, 213 participants were randomised to screening for suicidal ideation and 230 to control questions. There were no deviations from random allocation, and data on one person (aged 16) who was erroneously randomised were included in the analysis. Baseline characteristics of those randomised to each arm of the trial are presented in Table 1.

Follow-up data were obtained on the primary outcome measure for $351(79.2 \%)$ participants. Characteristics of those who were and were not followed up at 2 weeks are presented in Table 2. Demographic characterises and mental health of those who were and were not followed up appear to be similar.

At the 2-week follow-up interview, $46(28.0 \%)$ of those randomised to screening for suicidal ideation and 45 (24.1\%) of those randomised to control questions reported feeling that their life was not worth living $(\mathrm{OR}=1.23,95 \% \mathrm{CI}$ 0.76-1.98). Of those randomised to questions on suicidal ideation, 38 (23.2\%) reported wishing they were dead compared with 43 (22.9\%) of those randomised to questions on health and lifestyle $(\mathrm{OR}=1.01,95 \% \mathrm{CI}$ 0.61-1.66). Of those screened for suicidal ideation, $24(14.7 \%)$ reported having thought of taking their life compared with $21(11.3 \%)$ asked questions on health and lifestyle $(\mathrm{OR}=1.36,95 \% \mathrm{CI} 0.72-2.54)$. One person who was randomised to control questions reported having attempted to take their life at follow-up; no one among those randomised to screening for suicidal ideation reported having done so. 


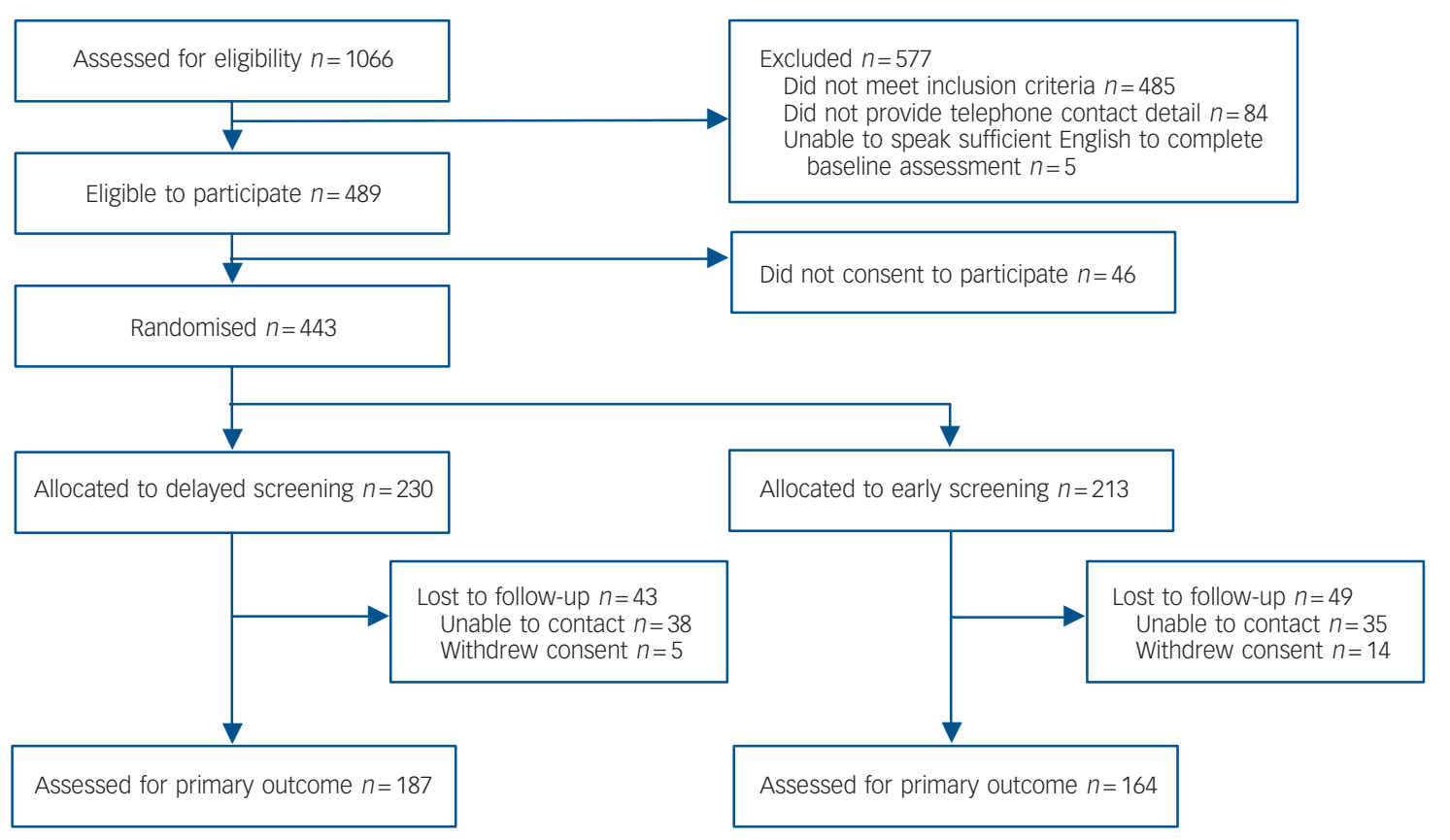

Fig. 1 Trial profile.

Among those who were randomised to baseline screening for suicidal ideation and followed up, 37 (22.5\%) of 164 people reported thinking about taking their life during the previous 2 weeks. Of 164 participants, $24(14.6 \%)$ reported thinking about taking their life 2 weeks later, and $5(3.9 \%)$ of 129 people who denied thinking about ending their life at baseline reported thinking so during the 2 weeks after screening. In contrast, 17 (45.9\%) of the 37 people who had thought about ending their life at baseline denied having this thought at follow-up.

Factors associated with feeling life was not worth living adjusted for clustering at the level of general practice are presented in Table 3. The odds of feeling that life was not worth living

\begin{tabular}{|c|c|c|c|}
\hline Characteristic & $\begin{array}{l}\text { Screening for suicidal ideation } \\
\qquad n=230\end{array}$ & $\begin{array}{l}\text { Questions on health and lifestyle } \\
\qquad n=213\end{array}$ & $\begin{array}{l}\text { Difference in means } \\
\text { or proportions }(95 \% \mathrm{Cl})\end{array}$ \\
\hline Age, years: mean (s.d.) & $48.5(18.4)$ & $48.4(18.4)$ & $0.07(-3.5$ to 3.4$)$ \\
\hline Women, $n(\%)$ & $157(69.2)$ & $149(70.0)$ & $-0.8(-9.3$ to 7.7$)$ \\
\hline Not married, $n$ (\%) & $125(54.3)$ & $127(59.6)$ & $-5.3(-14.3$ to 3.9$)$ \\
\hline Completed higher education, $n(\%)$ & $70(31.8)$ & $76(37.1)$ & $5.3(-3.6$ to 14.2$)$ \\
\hline \multicolumn{4}{|l|}{ Employment $^{\mathrm{a}} n$ (\%) } \\
\hline Employed or in education & 101 (47.2) & 100 (48.3) & $-1.1(-110.6$ to 8.4$)$ \\
\hline Unemployed & $67(31.3)$ & 67 (32.4) & $-1.1(-9.9$ to 7.8$)$ \\
\hline Retired & $46(21.5)$ & $40(19.3)$ & $2.2(-5.5$ to 9.8$)$ \\
\hline GHQ score, mean (s.d.) & $5.3(3.7)$ & $5.8(3.6)$ & $0.6(-1.2$ to 1.3$)$ \\
\hline
\end{tabular}

\begin{tabular}{|c|c|c|c|}
\hline Characteristic & $\begin{array}{l}\text { Followed up } \\
\qquad n=351\end{array}$ & $\begin{array}{c}\text { Not followed up } \\
n=92\end{array}$ & $\begin{array}{l}\text { Difference in means } \\
\text { or proportions }(95 \% \mathrm{Cl})\end{array}$ \\
\hline Age, years: mean (s.d.) & $49.2(18.6)$ & $45.4(17.2)$ & $3.9(-0.5$ to 8.2$)$ \\
\hline Women, $n$ (\%) & $245(69.8)$ & $61(68.5)$ & $1.3(-8.8$ to 12.5$)$ \\
\hline Not married, $n$ (\%) & $197(56.1)$ & $55(59.8)$ & $-3.7(-14.4$ to 7.8$)$ \\
\hline Completed higher education, $n$ (\%) & $112(32.9)$ & $34(40.0)$ & $-7.1(-18.7$ to 4.0$)$ \\
\hline \multicolumn{4}{|l|}{ Employment, $n$ (\%) } \\
\hline Employed or in education & $151(44.7)$ & $50(60.2)$ & $-15.6(-26.7$ to -3.5$)$ \\
\hline Unemployed & $116(34.3)$ & $18(18.1)$ & $12.6(1.5$ to 21.8$)$ \\
\hline Retired & $71(21.0)$ & $15(18.1)$ & $2.9(-7.4$ to 11.2$)$ \\
\hline GHQ score, mean (s.d.) & $5.5(3.7)$ & $5.5(3.6)$ & $0.01(-0.8$ to 0.9$)$ \\
\hline
\end{tabular}


Table 3 Factors associated with feeling life is not worth

living among 351 study participants who completed follow-up interviews

\begin{tabular}{|c|c|c|c|c|}
\hline Factor & $\begin{array}{l}\text { Odds } \\
\text { ratio }\end{array}$ & $\begin{array}{l}\text { Standard } \\
\text { error }\end{array}$ & $95 \% \mathrm{Cl}$ & $P$ \\
\hline $\begin{array}{l}\text { Screened for suicidal } \\
\text { ideation at baseline }\end{array}$ & 0.88 & 0.13 & $0.66-1.18$ & 0.38 \\
\hline \multicolumn{5}{|l|}{ General practice } \\
\hline Practice 1 & Reference & - & - & - \\
\hline Practice 2 & 0.75 & 0.08 & $0.61-0.93$ & 0.01 \\
\hline Practice 3 & 1.67 & 0.26 & $1.22-2.27$ & 0.01 \\
\hline Practice 4 & 0.82 & 0.07 & $0.69-0.97$ & 0.02 \\
\hline $\begin{array}{l}\text { Psychiatric caseness } \\
\text { according to GHQ }\end{array}$ & \multicolumn{3}{|c|}{ Psychiatric caseness } & $<0.001$ \\
\hline \multicolumn{5}{|l|}{ Probable personality } \\
\hline \multicolumn{5}{|l|}{ Employment status } \\
\hline Unemployed & reference & - & - & - \\
\hline Employed & 0.13 & 0.07 & $0.05-0.37$ & $<0.001$ \\
\hline Retired & 0.95 & 0.45 & $0.38-2.38$ & 0.91 \\
\hline Living alone & 0.51 & 0.22 & $0.22-1.19$ & 0.12 \\
\hline \multicolumn{5}{|l|}{ Interactions } \\
\hline $\begin{array}{l}\text { Suicide screening } \times \\
\text { employed } \\
\text { Suicide screening } \times\end{array}$ & 4.72 & 4.40 & $0.76-29.30$ & 0.10 \\
\hline $\begin{array}{l}\text { retired } \\
\text { Living alone } x\end{array}$ & 0.42 & 0.04 & $0.35-0.52$ & $<0.001$ \\
\hline employed & 6.19 & 6.30 & $0.84-45.48$ & 0.07 \\
\hline $\begin{array}{l}\text { Living alone } x \\
\text { unemployed }\end{array}$ & 7.33 & 8.45 & $0.76-70.22$ & 0.08 \\
\hline
\end{tabular}

among those screened for suicidal ideation compared with those asked questions on health and lifestyle was 0.88 (95\% CI $0.66-$ 1.18). In this model, the thought that life was not worth living at follow-up varied between the four general practices and was strongly associated with baseline mental health and the presence of probable personality disorder. Associations between the primary outcome with age and level of social support were not found. An interaction between being randomised to screening for suicidal ideation and employment status was found, suggesting that among those who were screened at baseline, suicidal ideation at follow-up was less likely among those who were retired compared with those who were unemployed. Interactions between personality status and age and the impact of being screened for suicidal ideation during the baseline interview were not found.

\section{Discussion}

Our findings confirm that many people who have signs of depression and are treated in primary care experience suicidal ideation. More than 1 in 8 people who took part in the study reported that they had thought of taking their life during the previous 2 weeks, although fewer than 1 in 20 reported having given serious consideration to ending their life. We found no evidence to support the view that screening for suicidal ideation among people in primary care leads to an increase in feelings that life is not worth living.

\section{Strengths and limitations}

The main strengths of the study were that it was randomised and that researchers collecting follow-up data were masked to allocation status. By focusing on people who had signs of depression, we included those patients for whom screening for suicidal ideation has been recommended. ${ }^{6}$ We focused our collection of follow-up data on the first 2 weeks after screening because data from observational studies suggest that if increases in suicidal ideation were to be found it would be within this period. $^{14}$

There are four main limitations associated with the study design. First, although we achieved the study sample we aimed to recruit and this was sufficient to detect clinically important differences in thoughts that life was not worth living, the power of the study was insufficient to explore differences in subgroups of patients, or to detect differences in other aspects of suicidal ideation or behaviour. With an incidence of 3 per 1000 in the 2-week period that we studied, we would have needed to have randomised over a million people to have had sufficient power to examine differences in the incidence of self-harm during this period. However, feelings that life is not worth living provide a sensitive (if not specific) indication of those at increased risk of suicidal behaviour ${ }^{24}$ and we believe that this outcome provided a sensitive measure of the potential impact of screening on the emotional health of study participants.

Second, we could not collect baseline data on levels of suicidal ideation or behaviour among those randomised to questions on health and lifestyle, as to do so would have undermined the central aim of the study. As a result, we do not know whether levels of suicidal ideation differed between study groups at baseline. However, we were able to assess general mental health, a factor which was strongly associated with suicidal ideation, and we believe that the adjusted odds ratios we have presented therefore provide a more accurate estimate of the true relationship between screening and future suicidal ideation.

Third, study participants were all recruited from relatively deprived inner-city practices. Almost $40 \%$ of adults of working age that took part in the study were unemployed. Although we have no reason to believe that screening for suicidal ideation would be associated with different outcomes among people living in less deprived areas, we cannot be certain of this.

Finally, the method we used to screen for suicidal ideation in the study differed from the approach that would normally be taken in clinical practice. Interviews with participants were conducted on the telephone after their visit to the GP rather than face to face as part of a clinical consultation. Although the external validity of the study would have been greater if participants had been asked about suicidal thoughts during the session with the doctor, GPs told us that it would be impractical for them to randomise patients during the clinical consultation.

\section{Clinical implications}

This is the first time that the impact of screening for suicidal ideation has been examined experimentally among adults. However, a previous attempt was made to examine the impact of screening school-aged children for risk of suicide using a selfcompleted questionnaire. ${ }^{30}$ Two days after completing the survey, the mental health of those that had been asked questions about suicidal thoughts was no worse than that of children who had not been asked these questions. As with our study, confidence limits around the odds ratio for suicidal ideation were broad $(\mathrm{OR}=1.2,95 \%$ CI $0.72-2.00)$, but sufficient for the authors to conclude that screening did not increase the likelihood of such thoughts. ${ }^{30}$

Although our findings have implications primarily for those working in primary care settings, we believe that in the absence of evidence on the impact of screening for suicidal ideation in general hospital settings, these data have wider implications. 
Researchers investigating the epidemiology of suicidal behaviour face a variety of ethical challenges, ${ }^{31}$ and concerns about the impact of assessing suicidal ideation in research projects have been raised in the past. ${ }^{32}$ Ethics committees have expressed concerns about the impact of research participants being asked such questions, and these findings may help reassure those reviewing proposals for new studies that asking questions about risk of suicide does not appear to have a short-term detrimental effect on people's mental health.

Among those who were randomised to screening for suicidal ideation, we found that very few people who did not have thoughts of ending their life at baseline reported having these thoughts at follow-up. In contrast almost half of those who reported thinking of ending their life at baseline denied having this thought during the following 2 weeks. These findings support those of a population-based study by Gunnell and colleagues who found that most people who experience thoughts of ending their life no longer do so 18 months later. ${ }^{33}$ They also provide support for the view that 'watchful waiting' of those with suicidal ideation is appropriate in primary care, in the absence of firmer evidence of risk of suicide such as a suicide plan. ${ }^{6}$

Although these data provide evidence that screening for suicidal ideation does not have an impact on the likelihood of subsequent suicidal ideation, they do not provide information about how patients feel about being asked such questions. For some healthcare practitioners and patients the topic of suicide remains a sensitive one $\mathrm{e}^{10,12}$ and such enquiry needs to be handled in a sensitive manner. Our data suggest that when these questions are asked in such a manner they do not appear to increase the likelihood of people starting to think their life may not be worth living.

This study did not examined whether screening for suicidal ideation in primary care leads to improved patient outcomes. Previous research examining the impact of a primary care-based intervention following self-harm found no evidence of patient benefit. ${ }^{34}$ Further research is required to examine the process and outcomes of screening for suicide risk in primary care to establish the impact of current guidelines which advocate this practice.

In summary, screening for risk of suicide does not appear to increase the likelihood of a person having thoughts that life is not worth living. Primary care workers should have the confidence to screen for suicide risk among people with signs of depression.

\footnotetext{
Mike J. Crawford, MD, Lavanya Thana, BSC, Faculty of Medicine, Imperial College London; Caroline Methuen, MRCPsych, Faculty of Medicine, Imperial College London, and Central and North West London NHS Foundation Trust; Pradip Ghosh MRCPsych, West London Mental Health NHS Trust; Sian V. Stanley, MRCGP, Faculty of Medicine, Imperial College London; Juliette Ross, MRCGP, Wembley Park Drive Medical Centre; Fabiana Gordon, PhD, Grant Blair, MRCGP, Faculty of Medicine, Imperial College London; Priya Bajaj, MRCPsych, Faculty of Medicine, Imperial College London, and Central and North West London NHS Foundation Trust, UK.

Correspondence: Dr M. J. Crawford, Reader in Mental Health Services Research, Centre for Mental Health, Faculty of Medicine, Imperial College London, Claybrook Centre, 37 Claybrook Road, London W6 8LN, UK. Email:m.crawford@imperial.ac.uk

First received 10 Jun 2010, final revision 24 Dec 2010, accepted 17 Jan 2011
}

\section{Funding}

The study was funded by an educational grant from Imperial College London and supported by St Mary's Paddington Charitable Trust.

\section{Acknowledgements}

We thank Christine Lyons, Elena Borreani and Melissa Patel for their help with data collection.

\section{References}

1 World Health Organisation. Mental Health: Facts and Figures: Suicide Prevention. WHO, 2006.

2 Appleby L, Shaw J, Amos T, McDonnell R, Harris C, McCann K, et al. Suicide within 12 months of contact with mental health services: national clinical survey. BMJ 1999; 318: 1235-9.

3 Luoma JB, Martin CE, Pearson JL. Contact with mental health and primary care providers before suicide: a review of the evidence. Am J Psychiatry 2002; 159: 909-16.

4 Oxman TE, Dietrich AJ, Schulberg HC. The depression care manager and mental health specialist as collaborators within primary care. Am J Geriatr Psychiatry 2003; 11: 507-16.

5 Jenkins R, Kovess, V. Evaluation of suicide prevention: a European approach. Int Rev Psychiatr 2002; 14: 34-41.

6 National Institute for Clinical Excellence. Depression: Management of Depression in Primary and Secondary Care. Clinical Guideline 23. NICE, 2004.

7 Williams Jr JW, Noel PH, Cordes JA, Ramirez G, Pignone M. Is this patient clinically depressed? JAMA 2002; 287: 1160-70.

8 Schulberg HC, Bruce ML, Lee PW, Williams Jr JW, Dietrich AJ. Preventing suicide in primary care patients: the primary care physician's role. Gen Hosp Psychiatry 2004; 26: 337-45.

9 Bryan CJ, Corso KA, Rudd MD, Cordero LC. Improving identification of suicidal patients in primary care through routine screening. Prim Care Community Psychiatr 2008; 13: 143-7.

10 Feldman MD, Franks P, Duberstein PR, Vannoy S, Epstein R, Kravitz RL. Let's not talk about it: suicide enquiry in primary care. Ann Fam Med 2007; 5 412-8.

11 Stoppe G, Sandholzer H, Huppertz C, Duwe H, Staedt J. Family physicians and the risk of suicide in the depressed elderly. J Affect Disord 1999; 54: 193-8.

12 Bajaj P, Borreani E, Ghosh P, Methuen C, Patel M, Crawford MJ. Screening for suicidal thoughts in primary care: the views of patients and general practitioners. Ment Health Fam Med 2009; 4; 229-35.

13 Taiminen $\mathrm{TJ}$, Helenius $\mathrm{H}$. Suicide clustering in a psychiatric hospital with a history of a suicide epidemic: a quantitative study. Am J Psychiatry 1994; 151: 1087-8.

14 Hawton K, Simkin S, Deeks JJ, O'Connor S, Keen A, Altman DG, et al. Effects of a drug overdose in a television drama on presentations to hospital for self poisoning: time series and questionnaire study. BMJ 1999; 318: 972-7.

15 Pirkis JE, Burgess PM, Francis C, Blood RW, Jolley DJ. The relationship between media reporting of suicide and actual suicide in Australia. Soc Sci Med 2006; 62: 2874-86.

16 Cheng AT, Hawton K, Lee CT, Chen TH. The influence of media reporting of the suicide of a celebrity on suicide rates: a population-based study. Int J Epidemiol 2007; 36: 1229-34.

17 Getz L, Sigurdsson JA, Hetlevik I. Is opportunistic disease prevention in the consultation ethically justifiable? BMJ 2003; 327: 498-500.

18 U.S. Preventive Services Task Force. Screening for suicide risk: recommendation and rationale. Ann Intern Med 2004; 140: 820-1.

19 London Research Centre. London's Demography. London Research Centre, 2005 (http://geography.radley.org.uk/london/Demography.pdf).

20 Arroll B, Khin N, Kerse N. Screening for depression in primary care with two verbally asked questions: cross sectional study. BMJ 2003; 327: 1144-6.

21 Goldberg D. The Detection of Psychiatric Illness. Oxford University Press, 1972.

22 Goldberg D, Williams P. A User's Guide to the General Health Questionnaire. nferNelson, 1991.

23 Jenkins R, Bebbington $\mathrm{P}$, Brugha TS, Farrell M, Lewis G, Meltzer H. British psychiatric morbidity survey. Br J Psychiatry 1998; 173: 4-7.

24 Thomas HV, Crawford M, Meltzer H, Lewis G. Thinking life is not worth living. A population survey of Great Britain. Soc Psychiatry Psychiatr Epidemiol 2002; 37: 351-6.

25 Crawford MJ, Nur U, McKenzie K, Tyrer P. Suicidal ideation and suicide attempts among ethnic minority groups in England: results of a national household survey. Psychol Med 2005; 35: 1369-77.

26 Hawton K, Catalan J. Attempted Suicide. A Practical Guide to its Nature and Management. Oxford University Press, 1987

27 Kahn RF. Diet and Habit Assessment. University of Arkansas, 2004.

28 Moran P, Leese M, Lee T, Walters P, Thornicroft G, Mann A. Standardised Assessment of Personality - Abbreviated Scale (SAPAS): preliminary validation of a brief screen for personality disorder. Br J Psychiatry 2003; 183: $228-32$. 
29 Stansfeld S, Marmot M. Deriving a survey measure of social support: the reliability and validity of the Close Persons Questionnaire. Soc Sci Med 1992 35: 1027-35.

30 Gould MS, Marrocco FA, Kleinman M, Thomas JG, Mostkoff $K$, Cote J, et al. Evaluating iatrogenic risk of youth suicide screening programs: a randomized controlled trial. JAMA 2005; 293: 1635-43.

31 Mishara BL, Weisstub DN. Ethical and legal issues in suicide research. Int J Law Psychiatry 2005; 28: 23-41.
32 Lakeman R, Fitzgerald M. Ethical suicide research: a survey of researchers Int J Ment Health Nurs 2009; 18: 10-7.

33 Gunnell D, Harbord R, Singleton N, Jenkins R, Lewis G. Factors influencing the development and amelioration of suicidal thoughts in the general population. Cohort study. Br J Psychiatry 2004; 185: 385-93.

34 Bennewith B, Stocks N, Gunnell D, Peters TJ, Evans MO, Sharp DJ. General practice based intervention to prevent repeat episodes of deliberate self harm: cluster randomised controlled trial. BMJ 2002; 324: 1254-62. psychiatry

in the Old

Testament

\section{King David: an episode of acute stress disorder during the brief life and premature death of Bathsheba's baby}

\section{George Stein}

The second book of Samuel tells the story of how King David took a fancy to Bathsheba who was at the time the wife of another man. When their first child was born, David became abruptly mute, refused to eat or drink and appeared to be considering suicide for a brief period. However, as soon as the child had died he recovered quickly, a picture suggestive of an ICD-10 acute stress disorder.

2 Sam. 11:2 'It happened, late one afternoon, when David rose from his couch, and was walking about on the roof of the King's house that he saw a woman bathing; the woman was very beautiful. 3 David sent someone to inquire about the woman. It was reported 'This is Bathsheba daughter of Eliam, the wife of Uriah the Hittite'. 4 So David sent messages to fetch her and she came to him and he lay with her. (Now she was purifying herself after her period.) Then she returned to her house. 5 The woman conceived and she sent and told David "I am pregnant." '

The story goes on describe how David gets rid of Uriah, by arranging for him to be sent to the front in the war against the Aramaeans where the fighting was most intense and where a certain death in battle awaited him:

11:26 'When the wife of Uriah heard that her husband was dead, she made lamentation for him. 27 When the mourning was over David sent and brought her to his house and she became his wife and bore him a son. But the thing that David had done displeased the Lord and the Lord sent Nathan to David'.

The prophet Nathan admonished David for the crime of stealing Uriah's wife and then arranging for him to be killed and told him that he would be punished for it as 'the child that is born to you, shall die'.

12.15 'The Lord struck the child that Uriah's wife bore to David, and it became very ill. 16 David pleaded with God for the child; David fasted and went in and lay all night on the ground. The elders of his house stood besides him, urging him to rise from the ground: but he would not nor did he eat food with them. On the seventh day the child died. And the servants of David were afraid to tell him that the child was dead: for they said while the child was alive we spoke to him, and he did not listen to us; how then can we tell him the child is dead? He may do himself some harm.

When David hears that the child is dead he recovers rapidly and once more talks to his servants, then anoints himself and starts to eat again.

ICD-10 describes acute stress reaction (F43.0) as 'a transient disorder of significant severity which develops in an individual in response to exceptional physical and/or mental stress and which usually subsides within hours or days. The symptoms typically include an initial state of daze ... followed by further withdrawal from the surrounding situation (to the extent of a dissociative stupor) or by agitation or overactivity. Symptoms usually appear within minutes of the impact of the stressful stimulus and disappear within 2-3 days'. Following the birth of his baby David is acutely distressed, becomes dazed as he is mute; he fails to respond to his servants, nor does he eat or drink, and the servants think he may harm himself. However, the condition resolves very rapidly once the baby dies, with the whole episode lasting for less than 7 days.

The moral tutorial that the prophet Nathan gives to David that not even a king should lust after another man's wife has been often recounted by priests and rabbis over the ages, but the equally useful psychiatric tutorial on ICD-10 acute stress reaction as described in this ancient text is rarely, if ever, cited. 